\title{
Trends of Suicidal Death at a Tertiary Care Hospital in Bangladesh
}

\author{
Choudhury $\mathrm{MH}^{1}$, Rahman $\mathrm{MM}^{2}$, Hossain $\mathrm{MG}^{3}$, Tabassum $\mathrm{N}^{4}$, Islam $\mathrm{MR}^{5}$
}

\begin{abstract}
Background: Suicide is one of the forms of criminal offence in Bangladesh and it is also prevailing in other countries of the world. Objective: The purpose of the present study was to see the trends of suicidal death at a tertiary care hospital. Methodology: This retrospective study was conducted on suicidal death in the Department of Forensic Medicine at Dinajpur Medical College, Dinajpur. Result: A total number of 20 cases were examined from June 2004 to June 2006 for 2 years. All the cases were referred from 13 different police stations and one railway station of Dinajpur district. Among them the highest numbers of cases were brought by Kotowally police station and the lowest from Hakimpur police station. But among the 20 cases $70 \%$ were female Muslims. Conclusion: The highest frequency of offence is found in lower socioeconomic status. The most common age group is from 20-35 years. [J Shaheed Suhrawardy Med Coll, 2013;5(1):28-30]
\end{abstract}

Key words: Suicide, suicidal death, hanging, poisoning, drowning, criminal offense

Received: December 2012; Revised: March 2013; Accepted: May 2013

\section{Introduction}

Suicide usually means self destruction. Broadly it can be defined as ruin or harm suffered by a person, society on account of own action ${ }^{1}$. Whenever attempts to commit suicide and does any act towards the commission of such offence, it shall be punished with simple imprisonment for a term which may extend to one year or with fine or with both $^{2}$. Shooting, hanging and stabbing are a 'hard way' of committing suicide and typically a male choice; however poisoning and drowning are 'soft way' of committing suicide and typically a female choice ${ }^{3}$. Suicide may injure themselves in different ways. The pathologist must be always alert to the possibility that such injuries are not suicides; however, some manifestations of peculiar practices that have taken a cause unintended by the victim. Masochistic asphyxia is still some times mistaken for suicide $^{1}$. In this country the incidence of suicide is increasing day by day ${ }^{4}$ due to high birth rate, mortality and morbidity and the higher population growth rate ${ }^{5}$.

Suicide is no longer a criminal offence in many developed countries but continues to be so in many developing countries $^{6}$. Higher population pressures directly effects on countries economic growth, lack of education, unemployment and poverty ${ }^{4}$. The mortality of a man breaks down under certain conditions like social and economic insecurity, social stigma etc. The causes of suicides are not only related with the victims but also associated with other factors. Religious and social factors also continue to influence the diagnosis and registering of suicides $^{7}$. Families do not disclose the true nature of the act, due to fear of harassment by police and/or social stigma. Instead it is claimed as an accident or in some cases, a homicide ${ }^{5}$. The stigma of mental disease and psychiatric help-seeking further compounds the problem, leading to underreporting of suicides, which may be as high as $30.0 \%$ to $100.0 \%$.

Now-a-days different papers publish the incidence of suicide with importance though many cases are not reported due to social stigma, fear and prestige of the family. In fact, the suicidal death cases are much higher than the cases recorded by authority. The purpose of the present study was to measure the suicidal death at a tertiary care hospital in Bangladesh.

1. Dr. Md. Habibuzzaman Choudhury, Associate Professor, Department of Forensic Medicine, Shaheed Suhrawardy Medical College, Dhaka

2. Dr. Md. Mizanur Rahman, Associate Professor, Department of Forensic Medicine, Enam Medical College, Dhaka

3. Dr. Md. Gisan Hossain, Lecture, Department of Forensic Medicine, Enam Medical College, Dhaka

4. Dr. Nasid Tabassum, Assistant Professor, Department of Forensic Medicine, Z. H. Shikder Women's Medical College, Dhaka

5. Prof. Dr. Md. Rafiqul Islam, Professor, Department of Microbiology, Shaheed Suhrawardy Medical College, Dhaka

\section{Correspondence}

Dr. Md. Habibuzzaman Choudhury, Associate Professor, Department of Forensic Medicine, Shaheed Suhrawardy Medical College, She-E-Bangla Nagar, Dhaka, Bangladesh; Cell No.: +8801711593558

Conflict of interest: No conflict of interest has been declared by the authors. 


\section{Methodology}

This Retrospective study was carried out in the Department of Forensic Medicine at Dinajpur Medical College, Dinajpur from June 2004 to June 2006. Dinajpur Medical College, Dinajpur is a tertiary care government hospital in the northern part of Bangladesh. During these years all the medicolegal cases were referred from 13 different police stations (PS) and one railway station of Dinajpur district. The data were collected from the relatives of the victims. The record books of Forensic Medicine Department are maintained. All the data were double checked before entering into analysis. Different cases were searched in the record books to get the drowning cases. Only the cases which have complete information were included. Missing diagnosis, missing name, discharge on risk bond (DORB) and absconded cases were excluded from this study. Computer based statistical analysis were carried out with appropriate techniques and systems. All data were recorded systematically in preformed data collection form (questionnaire) and quantitative data were expressed as mean and standard deviation and qualitative data were expressed as frequency distribution and percentage. Statistical analysis was performed by using window based computer software devised with Statistical Packages for Social Sciences (SPSS-19) (SPSS Inc, Chicago, IL, USA).

\section{Results}

Total 20 cases were brought by different police stations of Dinajpur district to the Department of Forensic Medicine at Dinajpur Medical College for medicolegal examination. Total number of 20 suicidal cases were recorded in three years of which $7(35.0 \%)$ cases were reported in the year of $2004,6(30.0 \%)$ cases in the year of 2005 and $7(35.0 \%)$ cases in the year of 2006 (Table 1).

Table 1: Trends of Annual Suicidal Death

\begin{tabular}{ccc}
\hline Year & Frequency & Percentage \\
\hline 2004 & 07 & 35.0 \\
2005 & 07 & 35.0 \\
2006 & 06 & 30.0 \\
Total & $\mathbf{2 0}$ & $\mathbf{1 0 0 . 0}$ \\
\hline
\end{tabular}

The highest frequencies of victims were noted in age group 20-35 years which was $12(60.0 \%)$ cases (Table 2 ).

Table 2: Age Distribution among Study Population

\begin{tabular}{lcccc}
\hline Age Group & $\begin{array}{c}\mathbf{2 0 0 4} \\
\mathbf{n ( \% )}\end{array}$ & $\begin{array}{c}\mathbf{2 0 0 5} \\
\mathbf{n ( \% )}\end{array}$ & $\begin{array}{c}\mathbf{2 0 0 6} \\
\mathbf{n ( \% )}\end{array}$ & Total \\
\hline 0 to 20 Years & $2(50.0)$ & $1(25.0)$ & $1(25.0)$ & $4(100.0)$ \\
20 to 35 Years & $3(25.0)$ & $5(41.7)$ & $4(33.3)$ & $12(100.0)$ \\
36 to 40 Years & $2(50.0)$ & $1(25.0)$ & $1(25.0)$ & $4(100.0)$ \\
Total & $\mathbf{0 7 ( 3 5 . 0 )}$ & $\mathbf{0 7 ( 3 5 . 0 )}$ & $\mathbf{0 6 ( 3 0 . 0 )}$ & $\mathbf{2 0 ( 1 0 0 . 0 )}$ \\
\hline
\end{tabular}

* Figure within parenthesis indicates percentage.
Considering the socioeconomic status of the victims, it was found that the higher frequency of suicide was among the lower socio economic group which was 11(55.0\%) cases followed by middle socioeconomic status which was $5(25.0 \%)$.

Table 3: Distribution of the cases according to socioeconomic status

\begin{tabular}{lcccc}
\hline $\begin{array}{l}\text { socioeconomic } \\
\text { status }\end{array}$ & $\begin{array}{c}\mathbf{2 0 0 4} \\
\mathbf{n}(\boldsymbol{\%})\end{array}$ & $\begin{array}{c}\mathbf{2 0 0 5} \\
\mathbf{n}(\boldsymbol{\%})\end{array}$ & $\begin{array}{c}\mathbf{2 0 0 6} \\
\mathbf{n}(\boldsymbol{\%})\end{array}$ & Total \\
\hline Upper & $1(25.0)$ & $2(50.0)$ & $1(25.0)$ & $4(100.0)$ \\
Middle & $1(20.0)$ & $2(40.0)$ & $2(40.0)$ & $5(100.0)$ \\
Lower & $5(45.4)$ & $3(27.3)$ & $3(27.3)$ & $11(100.0)$ \\
Total & $\mathbf{0 7 ( 3 5 . 0 )}$ & $\mathbf{0 7 ( 3 5 . 0 )}$ & $\mathbf{0 6 ( 3 0 . 0 )}$ & $\mathbf{2 0 ( 1 0 0 . 0 )}$ \\
\hline
\end{tabular}

*Figure within parenthesis indicates percentage.

\section{Discussion}

Global suicide rates have shown a steady increase over the last 50 years and are projected to increase to 1.53 million by the year 20206. This is despite significant advancements in recognition and treatment of depression and other mental disorders and the introduction of more effective and safer psychotropics (including anti-depressants) and improvement in mental health services in many countries 5 . In countries like Finland and England suicide prevention programmes have successfully lowered suicide rates ${ }^{7}$.

In this study the higher frequency was from kotowally PS and the lowest from Hakimpur PS and this was collected according to police statistics. In Bangladesh suicide is increasing day by day. According to Bureau of police research and development number of suicides has been increasing continually in Bangladesh than the previous years ${ }^{8}$. The daily news paper are reported new cases of suicide. One study shows that victimization of suicides increases with middle age group as well as those who are socio economically lagging behind. Similar to the present study it has been offset by huge increases in suicides in many developing countries such as China and India ${ }^{9}$. However, there have been gains in suicide prevention in developed countries ${ }^{10}$.

Suicides, apart from poisoning may use or even more of the different methods like stabbing and cutting, firearm and explosives, jumping from height, burning, suffocation in plastic bags, hanging and strangulation, electrocution, road and railway injuries and drowning ${ }^{11}$. In the present study the way of suicidal death was not properly cited as because these were not properly recorded. Suicidal knife wounds may be incised and stab wounds are self inflected either from victims of self destructions, from mental aberrations or by deliberately for some form of gain. These are the wounds whose site and range are within the reach of the deceased arm, unless some device has been used to reach the trigger. The weapons must be present at the scene ${ }^{2}$.

In the present study it was found that the higher frequency 
of suicide was among the lower socioeconomic group which was $11(55.0 \%)$ cases followed by middle socioeconomic status which was $5(25.0 \%)$. This is due to mental pressure, economic stress as well as the environmental factors ${ }^{5}$. However, the suicidal wounds may be multiple. A suicidal cut throat usually has the trial of incision. Deliberate cutting of the wrist is rarely effective the sole method of suicide ${ }^{11}$. Suicidal knife wounds over the chest are almost always stab wounds. Suicidal knife wounds are not often made in the abdomen. Suicide by sub-mersion is a common mode of self destruction in both man and women. Suicide may be performed by asphyxia (hanging). Abetment of suicide is punishable under section 306 and attempt to commit suicide under section $309^{12}$. The term abetment has been defined under section 107 IPC where in it has stressed that there must be investigation; co-operation or intentional assistance given that would be suicide ${ }^{3}$.

It is also considered as unlawful homicide, since the accused is abetting or aiding the victim in committing suicide. It may be noted that if the person who wants to die asks another person to kill him, then it becomes culpable homicide only (i.e. by consent). During punishment for abetment of suicide, the person abetting suicide of another person, shall be punished with imprisonment up to 10 years and shall also be liable to fine ${ }^{12}$. Attempt to commit suicide if any act towards the commission of suicide is done, the punishment is imprisonment up to 1 year or fine or both ${ }^{13}$. Abetment of suicide of child or insane person the punishment is 10 years imprisonment ${ }^{3}$.

\section{Conclusion}

The highest frequency of suicidal offence is found in lower socioeconomic status. The age group of 20-35 years are most commonly committed suicide. Injuries that are deliberately self inflicted are common and their examination is a frequent task for both pathologist and clinical forensic practitioners. Suicide is the form of criminal offence. The abettor should be punished so that no incidence can occur in future.

\section{References}

1. Bernard Knight, self inflicted injuries, forensic pathology, 2nd edition, USA, Oxford university New York, page range : 227-232

2. Simpson, Firearm and Punctured Injury, Forensic Medicine, 12th edition, London, Arnold, odder head line group, page: 62-67

3. Krishan VI. Medicolegal injuries, Text Book of Forensic Medicine \& Toxicology 4 th edition page range : $260-275$

4. Faiz MA. Baseline survey on cases of poisoning and its outcome, reported on behalf of poison information center, Dhaka medical college, Dhaka, Bangladesh. 2007: 1-31

5. World Health Organization. The World Health Report 2001. Mental Health: New Understanding, New Hope. Geneva: WHO, 2001

6. Khan MM, Prince M. Beyond rates: the tragedy of suicide in Pakistan. Trop Doct 2003;33:67-9

7. Department of Health. National Suicide Prevention Strategy For England. London: DoH, 2002

8. Chowdhury FR, Rahman AU, Mohammed FR, Chowdhury A, Ahasan $\mathrm{H}$, Bakar MA. Acute poisoning in southern part of Bangladesh-The case load is decreasing. Bangladesh Medical Research Council Bulletin;2011;37(2):61-5

9. Bertolote JM, Fleischmann A. A global perspective on the epidemiology of suicide. Suicidologi 2002;7:6-8

10. Khan MM. Suicide prevention and developing countries. Royal Society of Medicine 2005 October 1, 2005;98(10):459-63

11. Rao NKG. Medicolegal, Text Book of Forensic Medicine page range 330-335

12. Reddy KSN. Medicolegal aspect of wounds, The Essentials of Forensic Medicine \& Toxicology,28th edition, Hydrabad, K Sugun Devi, 2009, page range: $252-258$

13. Yusuf HR, Akhter HH, Rahman MH, Chowdhury MK, Rochat RW. Injury related deaths amongst women aged 10-50 years in Bangladesh, 1996-97. Lancet 2000; 355:1220-4 